\title{
Central Transient Receptor Potential Vanilloid 4 Contributes to Systemic Water Homeostasis through Urinary Excretion
}

\author{
Hiromi Tsushima*,a $^{* a}$ and Mayumi Mori-Kawabe ${ }^{b}$ \\ ${ }^{a}$ Laboratory of Pharmacology, College of Pharmacy, Kinjo Gakuin University; 2-1723 Omori, Moriyama-ku, Nagoya \\ 463-8521, Japan: and ${ }^{b}$ Department of Cellular and Molecular Pharmacology, Nagoya City University Graduate \\ School of Medical Sciences; Kawasumi, Mizuho-ku, Nagoya 467-8601, Japan. \\ Received May 18, 2019; accepted August 10, 2019
}

Intracerebroventricular (icv) injection of transient receptor potential vanilloid 4 (TRPV4) agonists $4 \alpha$-phorbol-12, 13-didecanoate (4 $\alpha$-PDD) and GSK101690A increased urinary excretion under the physiological condition. TRPV4 antagonists ruthenium red and HC-067047 significantly blocked increased urinary volume after intragastric administration of water and 4 $\alpha$-PDD-induced diuresis. Administration of the TRPV4 agonists did not significantly change the plasma concentration of vasopressin or atrial natriuretic factor. Pretreatment with indomethacin inhibited the diuresis induced by $4 \alpha$-PDD. Moreover, icv injection of prostaglandin (PG) $F_{2 \alpha}$ produced diuretic effects. These findings indicate that central TRPV4 regulates urine excretion, which contributes to systemic water homeostasis in vivo. The underlying mechanisms are suggested to involve PG synthesis, but not release of vasopressin or atrial natriuretic factor.

Key words transient receptor potential vanilloid 4; systemic water homeostasis; urine excretion; prostaglandin; hypothalamus

\section{INTRODUCTION}

In 2000, Liedtke et al. demonstrated the possibility that transient receptor potential vanilloid 4 (TRPV4), a member of the TRPV subgroup in the TRP superfamily, is an osmotic sensor in the central nervous system (CNS). ${ }^{1)}$ This conclusion was derived from the facts that TRPV4 is opened/closed by changes in osmotic pressure and expressed in the vascular organ of the lamina terminalis, the preoptic area, and the subfornical area where the osmosensor is supposed to be present. $^{2-4)}$ Subsequently, some studies have supported the hypothesis that TRPV4 functions as an osmosensor. ${ }^{1,3,5,6)}$ Recently, TRPV4 was shown to possibly function as a volume sensor and not an osmosensor. ${ }^{7)}$ In any case, TRPV4 is involved in systemic water homeostasis. TRPV4 knockout (KO) mice were established by some laboratories. ${ }^{8-11)}$ However, because their phenotypes are inconsistent with each other, its role in systemic water homeostasis remains unclear.

Systemic water homeostasis is eventually established by the balance of intake and expulsion of water into and from the body, respectively. Large components of the intake and expulsion of water are the drinking water volume and urinary excretion, respectively, resulted from changes in osmotic pressure of body fluid. ${ }^{12)}$ We have already studied TRPV4 ligands in water intake by wild type (WT) animals, which suggested that TRPV4 contributes to systemic water homeostasis through regulation of the drinking water volume under the physiological condition. ${ }^{13}$ ) The present study was conducted to clarify the role of TRPV4 in regulation of urine outflow. In the CNS, a major mechanism to expel water may be mediated through osmoreceptors detecting changes in systemic osmotic pressure, followed by regulation of Arg-vasopressin (AVP) secretion, resulting in an increase or decrease in urinary volume. Osmoreceptors are present only on the cell bodies of vasopressin-containing neurons in supraoptic and paraven- tricular nuclei, but also at several sites in circumventricular organs of the CNS. ${ }^{2,3}$ If TRPV4 is an osmosensor or volume sensor, because TRPV4 is activated by decreased osmotic pressure, its opening should lead to polyuria. In this study, we examined the effects of TRPV4 ligands on urine outflow and AVP release using in-vivo system of wild-type animals.

\section{MATERIALS AND METHODS}

The study was conducted according to the Guidelines for the Care and Use of Laboratory Animals, and its protocol was approved by the Instructional Animal Care and Use of Committees of Nagoya City University Graduate School of Medical Sciences and Kinjo Gakuin University.

The main methods have been described elsewhere. ${ }^{13-17)}$ Here, they are explained briefly.

Animals Male Wistar rats (9-12-week old; SLC, Hamamatsu, Japan) were used in this study. They were kept in rooms maintained at $23 \pm 2{ }^{\circ} \mathrm{C}$ and $50 \pm 10 \%$ relative humidity with a 12-h light-dark cycle (light on from 8:00 a.m. to 8:00 p.m.).

Drug Administration All drugs were administered into the lateral cerebroventricle through a cannula. The cannula was fixed as follows. The rats were set in a stereotaxic instrument (Narishige Co., Ltd., Tokyo, Japan) after anesthesia with pentobarbiturate $(50 \mathrm{mg} / \mathrm{kg}$, intraperitoneal). A guide cannula (AG-8; Eicom Co., ltd., Kyoto, Japan) was inserted into the right lateral ventricle (coordinate: $5.8 \mathrm{~mm}$ anterior to lambda, $1.8 \mathrm{~mm}$ lateral to the midline and $2.8 \mathrm{~mm}$ ventral to the skull surface) according to the Atlas of Konig and Klippel ${ }^{18)}$ and fixed using dental cement. A dummy cannula (AD-8; Eicom Co., Ltd.) was placed in the guide cannula when experiments were not carried out. After 1 week of recovery, the rats were used for experiments. The cage for experiments was $30 \times 30 \times 30 \mathrm{~cm}$ surrounded by plastic boards. Its bottom was 
wire gauze to collect urine.

On the experimental day, the cannula for drug administration was inserted into the guide cannula instead of the dummy cannula without anesthesia at approximately 10:00 a.m. The drug administration cannula was connected to a $40-\mathrm{cm}$ polyethylene tube containing a drug $(10-13 \mu \mathrm{L})$, which was attached to a microsyringe. Then, the rats were placed in the experimental cage. During the experiment, the animals did not receive food or water. The drug solution was injected for $90 \mathrm{~s}$ at 10:30-11:00a.m. A pretreatment drug was injected at $0.5 \mathrm{~h}$ before $4 \alpha$-phorbol-12,13-didecanoate ( $4 \alpha$-PDD)/vehicle treatments.

Measurement of Urine Volume Urine was collected in a tray under the wire gauze of the experimental cage, and its volume was measured at $0.5,1.0,2.0,4.0$, and $6.0 \mathrm{~h}$ after drug administration. The measurements were carried out under basal or water-loaded conditions $(5 \mathrm{~mL} / 100 \mathrm{~g}$ body weight of water was administered using an intra-gastric catheter at 45 min before drug administration).

Measurement of Hormones The measurements were carried out according to the protocols of commercial ELISA kits [AVP: R\&D Systems Inc., MN, U.S.A.; atrial natriuretic factor (ANF): Peninsula Laboratories, Inc., CA, U.S.A.]. At 0.1 or $4 \mathrm{~h}$ after intracerebroventricular (icv) administration of $4 \alpha$-PDD, blood was collected into an ice-cold tube containing ethylenediaminetetraacetic acid (EDTA) and aprotinin from the trunk of ether-anesthetized animals after decapitation. The blood was centrifuged at $1600 \times \boldsymbol{g}$ and $4^{\circ} \mathrm{C}$, and then the plasma was stored at $-80^{\circ} \mathrm{C}$ until measurements. The hormones were extracted through a sep-pak C18 cartridge (Waters Co., MA, U.S.A.), according the manufacturer's instructions.

Statistics All data are expressed as means \pm standard error. Statistical analyses were carried out using one-way or two-way ANOVA, followed by post-hoc tests (Tukey-Kramer test) where appropriate to assess significance across groups (Statcell3 software added in Excel, Tokyo, Japan). Differences were considered significant at $p<0.05$.

Drugs and Reagents 4 $\alpha$-PDD (Alexis Biochemicals Co., San Diego, CA, U.S.A.); GSK1016790A and HC-067047 (GSK and HC; Cayman Chemical, Ann Arbor, MI, U.S.A.); ruthenium red (RR; Latoxan, Valence, France); indomethacin (IND) (Sigma-Aldrich Inc., St. Louis, MO, U.S.A.); prostaglandin $(\mathrm{PG}) \mathrm{E}_{2}, \mathrm{PGF}_{2 \alpha}$, and thromboxane $\mathrm{B}_{2}$ (Cayman Chemical Co., Ltd., MI, U.S.A.). The chemicals used were the highest grade. $4 \alpha$-PDD and PG were dissolved in dimethyl sulfoxide (DMSO) or ethanol and diluted with sterile physiological saline (Otsuka Chemicals, Tokyo, Japan). The final concentrations of DMSO and ethanol were 8 and 5\%, respectively. Indomethacin was dissolved in $0.1 \mathrm{~N} \mathrm{NaOH}$ and diluted by 20 -fold with phosphate buffered saline. The other drugs were dissolved in sterile physiological saline.

\section{RESULTS}

Effects of the TRPV4 Agonist and Antagonist on Urinary Excretion under the Basal Condition Figure 1A shows the urinary volume after icv injection of the TRPV4 agonist $4 \alpha$-PDD under the physiological condition without any treatments. This drug significantly increased urine outflow at $2-6 \mathrm{~h}$ after administration compared with vehicle administration. In addition, the $4 \alpha$-PDD-induced diuresis was dose dependent (Fig. 1B). As shown in Fig. 1C, TRPV4 antagonist ruthenium red (RR) completely blocked the $4 \alpha$-PDD-induced effect. RR itself did not influence the urinary volume. The selective TRPV4 agonist GSK1016790A (GSK, 50 ng) also produced the same diuresis that was relatively weaker than the diuresis induced by $20 \mu \mathrm{g} 4 \alpha$-PDD (Fig. 1B).

Because TRPV4 is activated by lower osmotic pressure than the physiological pressure, although TRPV4 is possible to detect cell volume, effects of TRPV4 antagonists themselves on the urinary volume were examined under a hypo-osmotic condition after the animals were loaded with water. As shown in Fig. 2A, under the water-loaded condition, the urinary volume was increased after vehicle administration. However, TRPV4 antagonists RR and HC-067047 (HC) significantly inhibited the increased urine outflow at the early period after administration compared with the vehicle-injected group (Figs. 2A, B). From approximately $2 \mathrm{~h}$ after administration, antagonistinjected groups gradually increased their urine excretion, and the total volume at $6 \mathrm{~h}$ after administration was not different compared with the vehicle-injected group.

Effects of $4 \alpha$-PDD on Plasma Concentrations of Hormones AVP and ANF powerfully regulate urine production under the physiological condition. Therefore, these hormones in plasma were measured after $4 \alpha$-PDD administration. However, no significant changes were observed between vehicleand $4 \alpha$-PDD-injected groups (Fig. 3).

Effects of a Cyclooxygenase Inhibitor on the 4a-PDD-Induced Diuresis To investigate mechanisms underlying the $4 \alpha$-PDD-induced diuresis, rats were pretreated with a cyclooxygenase (COX) inhibitor, IDN. As shown in Fig. 4A, IND significantly blocked the $4 \alpha$-PDD-induced diuresis. Next, we examined the influences on urine outflow after administration of some arachidonate metabolites into the lateral ventricle. $\mathrm{PGE}_{2}$ had a tendency to increase the urine volume, but it was not significant. However, icv injection of $\mathrm{PGF}_{2 \alpha}$ significantly induced diuresis, which was a relatively less potent effect with a shorter latency and duration than the $4 \alpha$-PDD-induced effect (Fig. 4B). Thromboxane (TX) $\mathrm{B}_{2}$ did not produce any significant effect on urine volume.

\section{DISCUSSION}

TRPV4 is a well-known, non-selective cation channel activated by various stimuli such as temperature, osmotic pressure, shear stress, and cell volume..$^{1-3,5,19-21)}$ In terms of osmotic stimuli, this channel is open under a lower pressure than the physiological pressure, and maximum opening is observed at approx. $220 \mathrm{mOsm} / \mathrm{kg}$ in TRPV4-transfected cells. ${ }^{1,5)}$ Recently, TRPV4 was reported to function as a cell volume sensor and not as an osmosensor. ${ }^{7)}$ In any case, TRPV4 open in vivo ultimately results in increasing the urine outflow volume and/or decreasing water intake. Our previous study showed that the TRPV4 agonist decreases water intake, and we concluded that TRPV4 participates in systemic water homeostasis through regulation of water intake. ${ }^{13)}$ In this study, we examined whether TRPV4 is involved in the homeostasis through regulatory mechanisms of urine outflow using the same methods. Injection of $4 \alpha$-PDD and GSK, which is a more selective TRPV4 agonist, into the ventricle resulted in diuresis. Conversely, TRPV4 antagonists induced the opposite effect. In addition, the antagonists inhibited the agonist-induced diuresis. 
A)
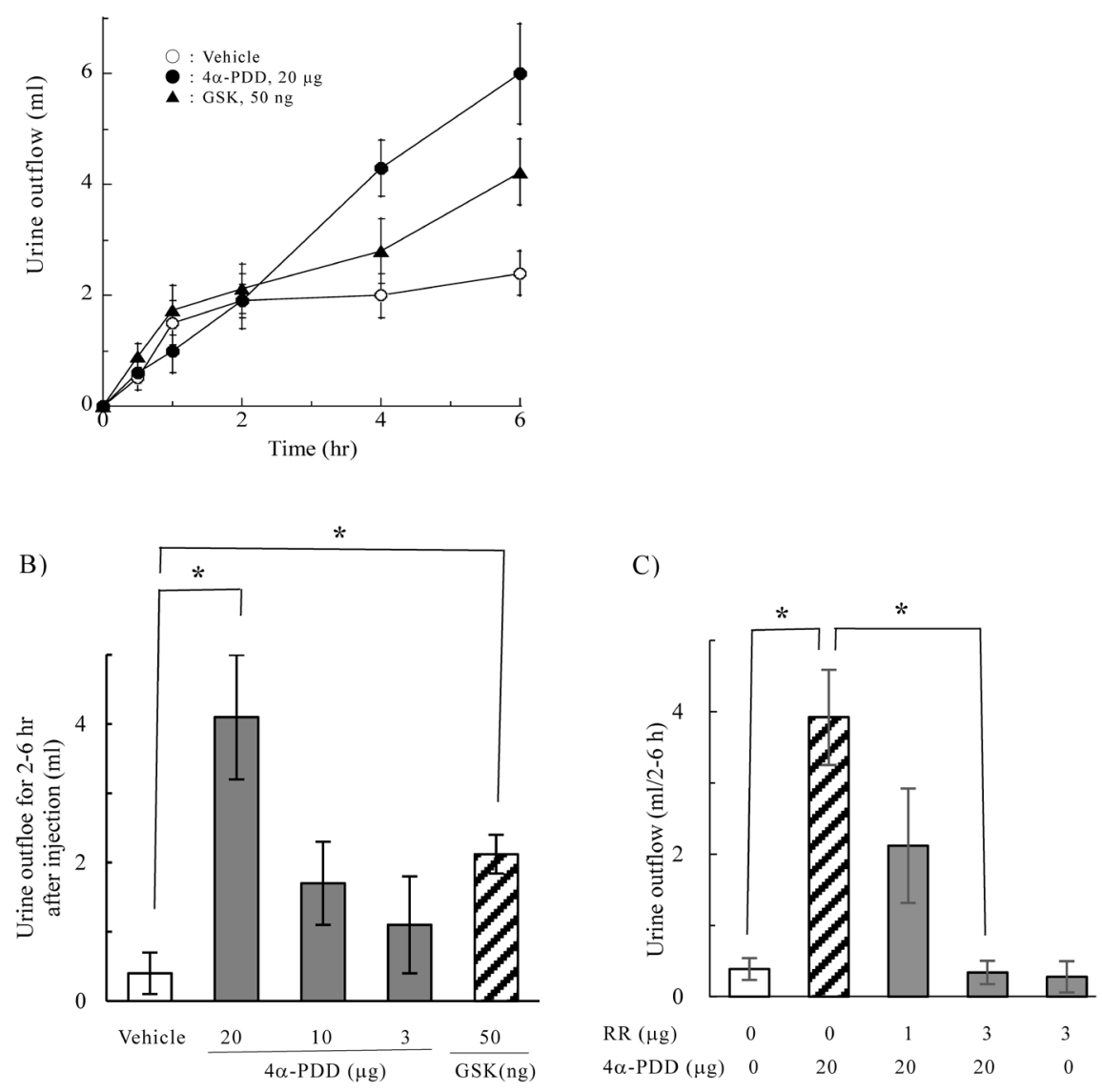

Fig. 1. Diuretic Effects after Administration of TRPV4 Agonists under the Physiological Condition

A) Intracerebroventricular (icv) injection of TRPV4 agonists, $4 \alpha$-PDD and GSK1016790A, significantly increased the urinary volume for 2-6h after injection compared with injection of the vehicle. $4 \alpha$-PDD: $N=8$; GSK: $N=8$; vehicle: $N=9$. B) The $4 \alpha$-PDD-induced diuresis was dose dependent at doses of 3-20 $\mu$ g. C) Pretreatment with ruthenium red (RR), a TRPV4 inhibitor, in the ventricle diminished the $4 \alpha$-PDD-induced diuretic effect dose-dependently. $4 \alpha$-PDD, $20 \mu \mathrm{g}: N=8 ; 10 \mu \mathrm{g}: N=6 ; 3 \mu \mathrm{g}: N=3$; GSK: $N=8$; vehicle: $N=9 ; 4 \alpha$-PDD: $N=8$; RR $(1 \mu \mathrm{g})+4 \alpha$-PDD: $N=4$; RR $(3 \mu \mathrm{g})+4 \alpha$-PDD: $N=5$; RR $(3 \mu \mathrm{g}): N=5$. $* p<0.05$ by Tukey-Kramer test after two-way ANOVA.

A)

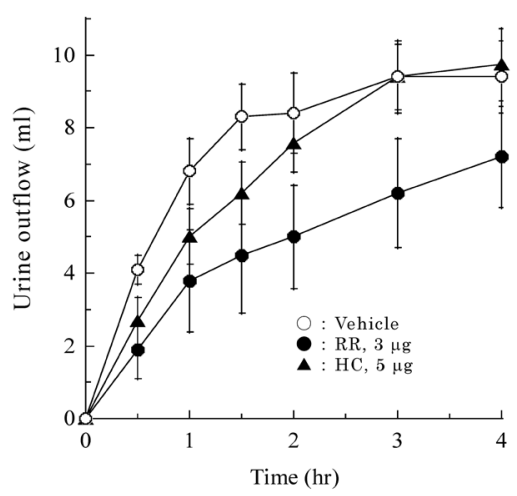

B)

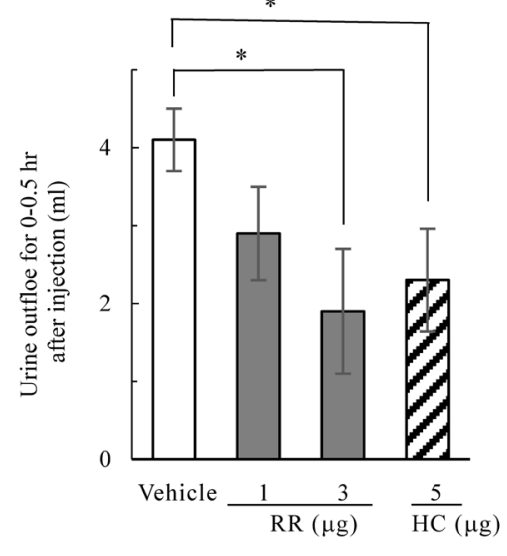

Fig. 2. Decreased Urinary Volume after Administration of TRPV4 Antagonists, RR and HC067047 (HC) under the Water-Loaded Condition

A) RR and HC administered into the ventricle diminished the increased urinary volume after oral administration of water. The same dose of RR inhibited the $4 \alpha-\mathrm{PDD}$ induced diuresis under the physiological condition (Fig. 1C). B) The effects were dose dependent. RR $(3 \mu \mathrm{g}): N=9 ; \mathrm{RR}(1 \mu \mathrm{g}): N=6 ; \mathrm{HC}(5 \mu \mathrm{g}): N=8 ;$ vehicle: $N=12$. $* p<0.05$ by Tukey-Kramer test after two-way ANOVA.

These results support the above hypothesis that TRPV4 in the CNS contributes to systemic water homeostasis through controlling both urinary and drinking water volumes.

The durations of the TRPV4 agonist- and antagonistinduced effects were $2-6$ and $0-0.5 \mathrm{~h}$ as shown in Figs. 1 and
2 , respectively. There is the time lag between these effects. This phenomenon is supposed to come from the difference in the experimental conditions. The experiments in Figs. 1 and 2 were carried out under the physiological condition and the water-loaded condition, respectively. Because the water-loaded 
A)

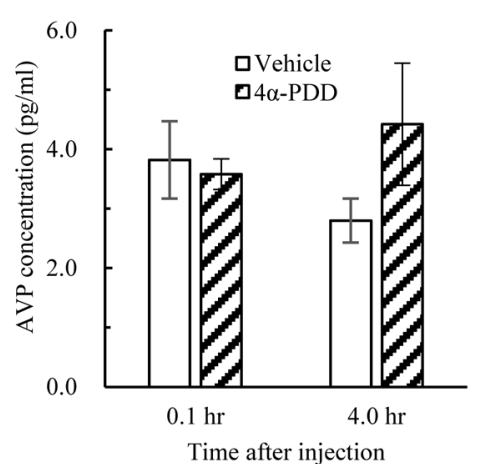

B)

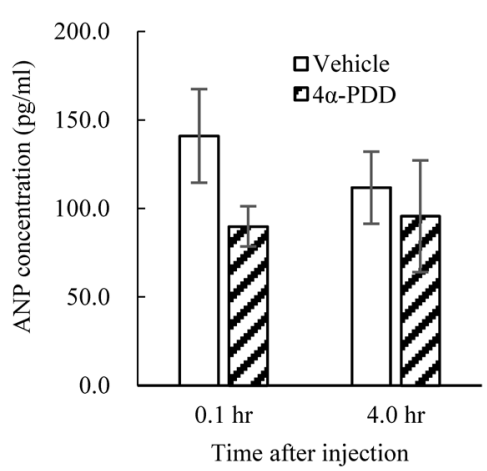

Fig. 3. Vasopressin (A) and Atrial Natriuretic Peptide (B) Concentrations in Plasma after 4 $\alpha$-PDD Administration under the Physiological Condition

Icv injection of $4 \alpha$-PDD increased the urinary volume at $2-6 \mathrm{~h}$ after injection under the normal physiological condition (Fig. 1). Blood was collected after decapitation at 0.1 and $4.0 \mathrm{~h}$ after injection and centrifuged $\left(1600 \times \boldsymbol{g}\right.$ at $\left.4{ }^{\circ} \mathrm{C}\right)$. The plasma was stored at $-80^{\circ} \mathrm{C}$ until measurements. The measurements were carried out using commercial ELISA kits. The plasma concentrations were not significantly influenced by the administration. A) $0.1 \mathrm{~h}$ : Vehicle $N=9 ; 4 \alpha-\mathrm{PDD} N=5 ; 4.0 \mathrm{~h}$ : Vehicle $N=11 ; 4 \alpha-\mathrm{PDD}$ $N=11$, B) 0.1 h: Vehicle $N=11 ; 4 \alpha$-PDD $N=6 ; 4.0$ h: Vehicle $N=9 ; 4 \alpha$-PDD $N=10$.

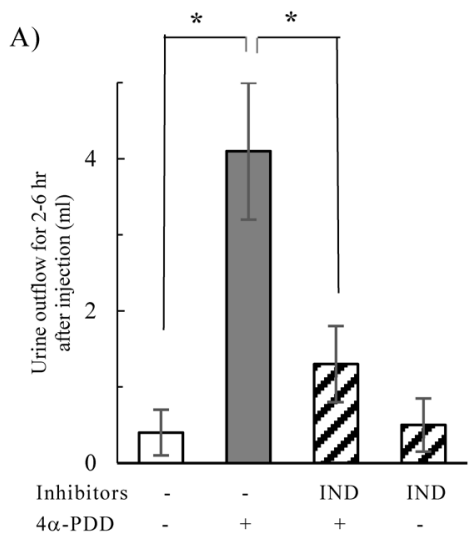

B)
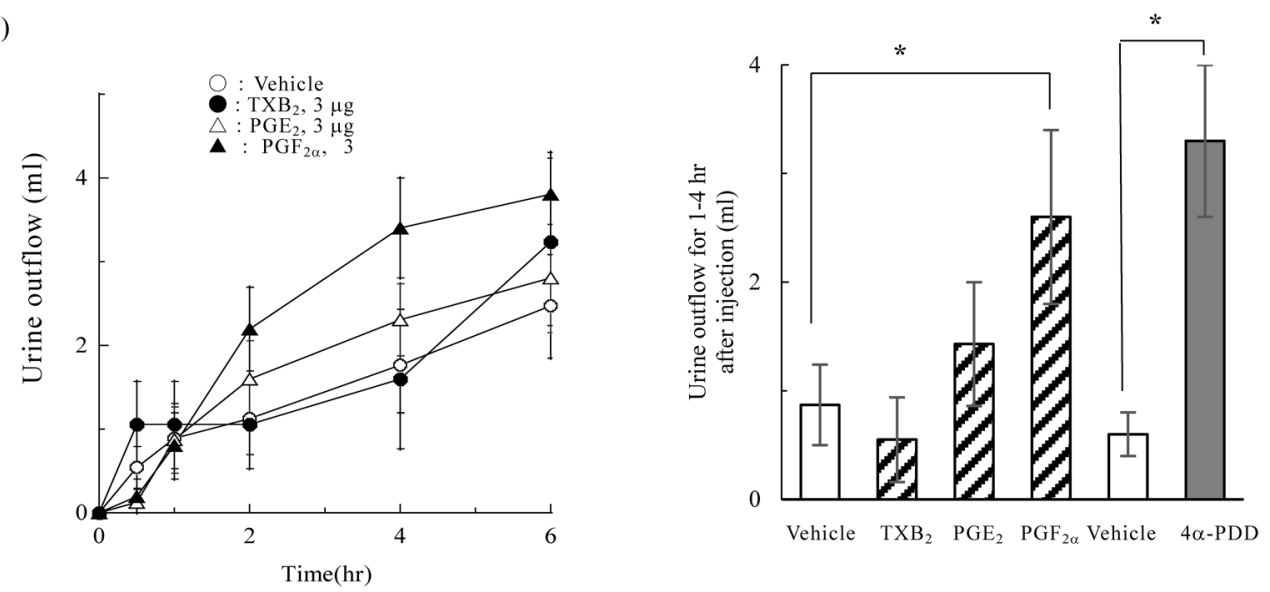

Fig. 4. Influences of Indomethacin on the $4 \alpha$-PDD-Induced Diuresis under the Physiological Condition

A) Pretreatments with indomethacin (15 $\mu \mathrm{g}$; IND) inhibited the $4 \alpha$-PDD-induced diuresis. $4 \alpha$-PDD: $N=8$; IND + 4 $\alpha$-PDD: $N=6$ IND: $N=6$; vehicle $N=9$. B) Effects of arachidonate metabolites thromboxane $\mathrm{B}_{2}\left(\mathrm{TXB}_{2}\right), \mathrm{PGE}_{2}$ and $\mathrm{PGF}_{2 \alpha}$ on the urinary volume. Icv injection of $\mathrm{PGF}_{2 \alpha}$ significantly increased the urinary volume. TXB $\mathrm{B}_{2}: N=6$; $\mathrm{PGE}_{2}: N=3 ; \mathrm{PGF}_{2 a}: N=6$; vehicle: $N=9 .{ }^{*} p<0.05$ by Tukey-Kramer test after one-way or two-way ANOVA.

condition elicits abnormal hypo-osmotic pressure of body fluid, many sensors, osmosensor, sensor for $\mathrm{Na}^{+}$concentration, cell volume sensor and so on, are already functioning to recover to the normal osmotic pressure. ${ }^{6,12,22-24)}$ At this time, the antagonist-induced effects will appear at relatively early time, and even if TRPV4, one of many sensors, is closed by its antagonist, its effect will be limited. On the other hand, be- cause these mechanisms do not activate under the physiological condition, the agonist-induced function is fully observed, although it took a while for the onset of diuresis from TRPV4 open.

Because AVP plays an important role in regulating urine production, the AVP concentration was measured after TRPV4 agonist administration. During the TRPV4 agonist-induced 
diuresis, AVP concentration is expected to decrease in the plasma, if the diuresis will be brought from its change. However, there was no significant change in the plasma concentration after administration of the TRPV4 agonist. Therefore, it is suggested that AVP is not involved in the TRPV4-induced regulation of urinary volume in WT animals. Studies of TRPV4 KO mice have measured the AVP concentration and/or urinary volume, and these in TRPV4 KO mice has been reported to be similar to that in WT mice under the physiological condition. ${ }^{11,18)}$ However, under hypertonic stimulation, Mizuno et al. found a higher AVP concentration in the plasma of KO mice than that in WT mice, ${ }^{11)}$ and the other reported opposing results. ${ }^{8,10)}$ Although they insist that TRPV4 is needed for systemic water homeostasis through urinary excretion, its role remains unclear. The discrepancy is probably due to differences in compensative functions, DNA damage in $\mathrm{KO}$ mice, and/or the hypertonic condition. TRPV4 is mostly closed, may be slightly opened by body temperature under physiological temperature and osmotic pressure, and open under the hypotonic condition. Thus, the effects under the hypertonic condition, which closes TRPV4 and renders the channel non-functional, may result in an increased compensatory function. Therefore, experiments using WT animals injected with agonists and antagonists are possible to exclude the compensatory function. This study showed that neither AVP nor ANP, which influence the urinary volume, were significantly changed after administration of the TRPV4 agonist. On the other hand, pretreatment with IND inhibited the $4 \alpha$-PDDinduced effect, and icv injection of $\mathrm{PGF}_{2 \alpha}$ produced diuresis to the same degree as $4 \alpha$-PDD. In the cultured aorta endothelial cells, an increase in $\mathrm{PGF}_{2 \alpha}$, not $\mathrm{PGE}_{2}$ or $\mathrm{TXB}_{2}$, after TRPV4 activation is reported. ${ }^{25)}$ Therefore, $\mathrm{PGF}_{2 \alpha}$ is suggested to play an important role in this TRPV4-induced effect. ${ }^{25)}$ However, because icv injection of $\mathrm{PGE}_{2}$ showed a tendency to produce diuresis, but not significantly, $\mathrm{PGE}_{2}$ may contribute in the effect. These suggest that increased PG biosynthesis, but not hormone release, is involved in TRPV4-mediated regulation of systemic water homeostasis through urine outflow. TRPV4 activation increases $\mathrm{Ca}^{2+}$ influx into cells, and this is supposed to activate phospholipase $\mathrm{A}_{2}$ and/or cyclooxygenase, followed by increases in biosynthesis of PGs. ${ }^{25-27)}$ TRPV4 is expressed in glial cells (astrocytes and microglia), neurons, and the endothelium ${ }^{20,28,29)}$ that are able to release PGs. ${ }^{30,31)}$ These cells are probably responsible for PG production after TRPV4 opening. In hypotonic or hypertonic condition, osmotic pressure changes not only in blood, but also in the cerebrospinal fluid and extracellular fluid. Therefore, glial cells are possible to detect its changes. Increases in PG production is possible to increase blood flow in the kidney, followed by diuresis. There are some reports that central administration of PGs increased urinary excretion, blood pressure, heart rate and sympathetic activity. ${ }^{32-34)}$ Also, it has been demonstrated that $\mathrm{PGE}_{2}$ increases aquaporin 2 expression through EP2 and/or EP4 receptors and then participates in the urinary concentration. ${ }^{35,36)}$ In addition, TRPV4, which was recently demonstrated to function as an anchor protein, binds to aquaporin and Kca channels. ${ }^{37-41)}$ These proteins may underlie the TRPV4-induced effect.

Osmosensation and its regulation involve many kinds of molecules. ${ }^{6,12,22-24)}$ Some recent reports demonstrate that TRPV1 play a role in systemic water homeostasis. TRPV1 may also detects changes in osmotic pressure as osmoreceptor. ${ }^{9,29,42-44)}$ In addition, TRPV1 is present in magnocellular neurons, and influences AVP release. ${ }^{20,37,42)}$ Therefore, TRPV1 is supposed to function in the regulatory mechanism in systemic water homeostasis with TRPV4. Especially, mechanism involving AVP release may need TRPV1.

In summary, TRPV4, at least, partly contributes to systemic water homeostasis of body fluid through regulation of urinary excretion in cooperation with regulation of water intake. The diuresis after TRPV4 open probably requires an increase in PG production, but not release of AVP or ANP.

Acknowledgments The authors would thank Sawako Mizoguchi, Yuka Honda and Hitomi Takahashi: Kinjo Gakuin University College of Pharmacy, for experimental assistant. This work was partly supported by grant-in-aid for Scientific Research from the Ministry of Education, Culture, Sports, Science, and Technology of Japan (No. 16659060 to HT) and from Salt Science Foundation (No. 0336 to HT; Tokyo, Japan).

Conflict of Interest The authors declare no conflict of interest.

\section{REFERENCES}

1) Liedtke W, Choe Y, Marti-Renom MA, Bell AM, Denis CS, Sali A, Hudspeth AJ, Friedman JM, Heller S. Vanilloid receptor-related osmotically activated channel (VR-OAC), a candidate vertebrate osmoreceptor. Cell, 103, 525-535 (2000).

2) Noda M, Sakuta H. Central regulation of body-fluid homeostasis. Trends Neurosci., 36, 661-673 (2013).

3) Sladek CD, Johnson AK. Integration of thermal and osmotic regulation of water homeostasis: the role of TRPV channels. Am. $J$. Physiol. Regul. Integr. Comp. Physiol., 305, R669-R678 (2013).

4) Voisin DL, Bourque CW. Integration of sodium and osmosensory signals in vasopressin neurons. Trends Neurosci., 25, 199-205 (2002).

5) Alessandri-Haber N, Yeh JJ, Boyd AE, Parada CA, Chen X, Reichling DB, Levine JD. Hypotonicity induces TRPV4-mediated nociception in rat. Neuron, 39, 497-511 (2003).

6) Sinke AP, Deen PM. The physiological implication of novel proteins in systemic osmoregulation. FASEB J., 25, 3279-3289 (2011).

7) Toft-Bertelsen TL, Krizaj D, MacAulay N. When size matter: transient receptor potentioal vanilloid 4 channel as a volume-sensor rather than an osmo-sensor. J. Physiol., 595, 3287-3302 (2017).

8) Janas S, Seghers F, Schaknan O, Alsady M, Deen P, Vriens J, Tissir F, Nillius B, Loffing J, Gailly P, Devuyst O. TRPV4 is associated with central rather than nephrogenic osmoregulation. Pflugers Arch., 468, 1595-1607 (2016).

9) Kinsman B, Cowles J, Lay J, Simmonds SS, Browning KN, Stocker SD. Osmoregulatory thirst in mice lacking the transient receptor potential Vanilloid type 1 (TRPV1) and/or type 4 (TRPV4) receptor. Am. J. Physiol. Regul. Integr. Comp. Physiol., 307, R1092-R1100 (2014).

10) Liedtke W, Friedman JM. Abnormal osmotic regulation in trpv4-/mice. Proc. Natl. Acad. Sci. U.S.A., 100, 13698-13703 (2003).

11) Mizuno A, Matsumoto N, Imai M, Suzuki M. Impaired osmotic sensation in mice lacking TRPV4. Am. J. Physiol. Cell Physiol., 285, C96-C101 (2003).

12) Jiao R, Cui D, Wang SC, Li D, Wang Y-F. Interactionns of the mechanosensitive channels with extracellular matrix, integrins, and cytoskeletal network in osmosensation. Frontiers in Mol. Neurosci., 10 (2017).

13) Tsushima H, Mori M. Antidipsogenic effects of a TRPV4 agonist, 
$4 \alpha$-phorbol 12, 13-didecanoate, injected into the cerebroventricle. Am. J. Physiol. Regul. Integr. Comp. Physiol., 290, R1736-R1741 (2006).

14) Tsushima $\mathrm{H}$, Mori M. Involvement of protein kinase $\mathrm{C}$ and tyrosine kinase in lipopolysaccharide-induced anorexia. Pharmacol. Biochem. Behav., 69, 17-22 (2001).

15) Tsushima H, Mori M, Fujiwara N, Moriyama A. Pharmacological characteristics of bombesin receptor mediating hypothermia in the central nervous system of a rats. Brain Res., 969, 88-94 (2003).

16) Tsushima H, Mori M. In vivo evidence that activation of tyrosine kinase is a trigger for lipopolysaccharide-induced fever in rats. Brain Res., 852, 367-373 (2000)

17) Tsushima H, Hotta $\mathrm{Y}$, Ando $\mathrm{H}$, Nonogaki T, Mori M. The roles of transient receptor potential vanniloid 4 (TRPV4) in the homeostasis of body fluid osmotic pressure. Issues in the psychology of motivation. (Paula R, Zelick R eds.) Nova Science Publishers, Inc., New York, pp. 219-228 (2007).

18) Konig LY, Klippel RA. The Rat Brain. A Stereotaxic Atlas of the Forebrain and Lower Parts of the Brain Stem. Williams and Wilkins, New York (1963).

19) Garcia-Elias A, Mrkonjić S, Jung C, Pardo-Pastor C, Vicente R, Valverde MA. The TRPV4 channel. Handbook Exp. Pharmacol., 222, 293-319 (2014).

20) Kanju P, Liedtke W. Pleiotropic function of TRPV4 ion channels in the central nervous system. Exp. Physiol., 101, 1472-1476 (2016).

21) Shibasaki K. TRPV4 ion channel as important cell sensors. $J$. Anesth., 30, 1014-1019 (2016).

22) Hoffmann EK, Pedersen SF. Sensors and signal transduction pathways in vertebrate cell volume regulation. Contrib. Nephrol., 152, 54-104 (2006).

23) Noda M, Sakuta H. Central regulation of body-fluid homeostasis. Trends Neurosci., 36, 661-673 (2013).

24) Cohen BE. Membrane thickness as a key factor contributing to the activation of osmosensors and essential Ras signaling pathways. Front. Cell Dev. Biol., 6, 76 (2018).

25) Zhang P, Sun C, Li H, Tang C, Kan H, Yang Z, Mao A, Ma X. TRPV4 (Transient receptor potential Vanilloid 4) mediates endothelium-dependent contraction in the aortas of hypertensive mice. Hypertension, 71, 134-142 (2018).

26) Leung GPH, Cheung KH, Leung CT, Tsang MW, Wong PYD. Regulation of epididymal principal cell functions by basal cells: roles of transient receptor potential (Trp) proteins and cyclooxygenase-1 (COX-1). Mol. Cell. Endocrinol., 216, 5-13 (2004).

27) Filosa JA, Yao X, Rath G. TRPV4 and the regulation of vascular tone. J. Cardiovasc. Pharmacol., 61, 113-119 (2013).

28) Bai J-Z, Lipski J. Involvement of TRPV4 channels in A $\beta 40$-induced hippocampal cell death and astrocytic $\mathrm{Ca}^{2+}$ signaling. Neurotoxicology, 41, 64-72 (2014).

29) Konno M, Shirakawa H, Iida S, Sakimoto S, Matsutani I, Kageyama K, Nakagawa T, Shibasaki K, Kaneko S. Stimulation of transient receptor potentioal vanilloid 4 channel suppresses abnormal activation of microglia induced by lipopolysaccharide. Glia, 60, 761-770 (2012)

30) Shiow LR, Favrais G, Schirmer L, Schang A-L, Cipriani S, Andres C, Wright J, Nobuta H, Fleiss B, Gressens P, Rowitch DH. Reactive astrocyte COX2-PGE2 production inhibits oligodendrocyte matura- tion in neonatal white matter injury. Glia, 65, 2024-2037 (2017).

31) Tzeng SF, Hsiao HY, Mak OT. Prostaglandins and cyclooxygenases in glial cells during brain inflammation. Curr. Drug Targets Inflamm. Allergy, 3, 335-340 (2005).

32) Fujimoto S, Endo Y, Hisada S. Centrally-mediated effects of prostaglandin A2 on urine outflow. Jpn. J. Pharmacol., 27, 325-326 (1977).

33) Feuerstein G, Helke CJ, Zerbe RL, Jacobowitz DM, Kopin IJ. Mechanisms involved in central cardiovascular effects of prostaglandin F2 alpha. Am. J. Physiol., 242, R545-R551 (1982).

34) MacNeil BJ, Jansen AH, Greenberg AH, Nance DM. Neuropeptide specificity of prostaglandin E2-induced activation of splenic and renal sympathetic nerves in rat. Brain Behav. Immun., 17, 442-452 (2003).

35) $\overline{\text { Gao } M}$, Cao R, Du S, Jia X, Zheng S, Huang S, Han Q, Liu J, Zhang X, Miao Y, Kang J, Gustafsson J-A, Guan Y. Disruption of prostaglandin E2 receptor EP4 impairs urinary concentration via decreasing aquaporin 2 in renal collecting duct. Proc. Natl. Acad. Sci. U.S.A., 112, 8397-8402 (2015).

36) Olesen ETB, Moeller HB, Assentoft M, MacAulay N, Fenton R. The vasopressin type 2 receptor and prostaglandin receptors EP2 and EP4 can increase aquaporin-2 plasma membrane targeting through a cAMP-independent pathway. Am. J. Physiol. Renal Physiol., 311, F935-F944 (2016).

37) Bansal V, Fisher TE. Osmotic activation of a $\mathrm{Ca}^{2+}$-dependent phospholipase $\mathrm{C}$ pathway that regulates $\Delta N$-TRPV1-mediated currents in rat supraoptic neurons. Physiological Reports, 5, e13259 (2017).

38) Feetham CH, Nunn N, Lewis R, Dart C, Barrett-Jolley R. TRPV4 and $\mathrm{KCa}$ ion channels functionally couple as osomosensor in the paraventricular nucleus. Br. J. Pharmacol., 172, 1753-1768 (2015).

39) Iuso A, Krizaj D. TRPV4-AQP4 interactions 'turbocharge' astrogrial sensitivity to small osmotic gradients. Channels, 10, 172-174 (2016).

40) Poole DP, Amadesi S, Veldhuis NA, Abogadie FC, Lieu TM, Darby W, Liedtke W, Lew MJ, McIntyre P, Bunnett NW. Protease-activated receptor 2 (PAR2) protein and transient receptor potential vanilloid (TRPV4) protein coupling is required sustained inflammatory signaling. J. Biol. Chem., 288, 5790-5802 (2013).

41) Benfenati V, Caprini M, Dovizio M, Mylonakou MN, Ferroni S, Ottersen OP, Amiry-Moghaddam M. An aquaporin-4/transient receptor potential vanilloid 4 (AQP4/TRPV4) complex is essential for cell-volume control in astrocytes. Proc. Natl. Acad. Sci. U.S.A., 108, 2563-2568 (2011).

42) Moriya T, Shibasaki R, Kamiya T, Takebuchi N, Ichimura M, Kitamura N, Asano A, Hosaka YZ, Forostyak O, Verkhratsky A, Dayanithi G, Shibuya I. Full-length transient receptor potential Vanilloid 1 channel mediate calucium signals and possibly contribute to osmoreception in vasopressin neurons in the rat supraoptic nucleus. Cell Calcium, 57, 25-37 (2015).

43) Sudbury JR, Ciura S, Sharif-Naeini R, Bourque CW. Osmotic and thermal control of magnocellular neurosecretary neurons-role of an N-terminal variant of trpvl. Eur. J. Neurosci., 32, 2022-2030 (2010).

44) Zaelzer C, Hua P, Prager-Khoutorsky M, Voisin DL, Leidtke W, Bourque CW. $\triangle N$-TRPV1: A molecular co-detector of body temperature and osmotic stress. Cell Reports, 13, 23-30 (2015). 